\title{
TWELFTH BIENNIAL INTERNATIONAL SEMINAR OF THE CANADIAN MATHEMATICAL CONGRESS
}

The 12 th Biennial International Seminar of the Canadian Mathematical Congress will be held at the University of British Columbia in Vancouver, Canada, from August 11 through August 27, 1969. This Seminar will be followed by the annual meeting of the Canadian Mathematical Congress at the University of Victoria, in Victoria, Canada, from August 28 through August 30.

The theme of the Seminar will be "Time Series and Stochastic Processes; Convexity and Combinatorics". Four series of Research Lectures at the post-doctoral level will be given: 'Dual processes and potential theory' by R.K. Getoor; 'Convexity and combinatorics' by V. L. Klee; 'Current problems in time series' by E. Parzen; 'Application of probability theory to other areas of mathematics' by A. Renyi. Three series of instructional lectures at the pre-doctoral level will be given: 'Frequency analysis of relations between stationary time series' by D.R. Brillinger; 'Markov chains : potentials and boundaries' by D. A. Dawson; 'Combinatorial graph theory: tree and extremal problems' by J. W. Moon.

Seminar participants, both graduate students and post-doctoral fellows, will be chosen primarily from Europe, the United States and Canada. Limited participant support will be available. The lectures and living accommodations will be located in the University Totem Park residence of the University of British Columbia. Further information about the Seminar and application forms may be obtained from

\author{
The Program Chairman, C. M. C. Seminar, \\ Professor Ronald Pyke, \\ Department of Mathematics, \\ University of Washington, \\ Seattle, \\ Washington 98105.
}

